\title{
BIOLOGICAL EFFECTS OF SOME CHITIN SYNTHESIS INHIBITORS ON CULEX PIPIENS (DIPTERA: CULICIDAE)
}

\author{
By
}

\author{
ABADA A. ASSAR, MAGDA M. ABO-ELMAHASEN, SHAYMAA H. MAHMOUD*, \\ AND AYAT I. YOUNES
}

Department of Zoology, Faculty of Science, Menoufia University, Shebin El-Kom, Egypt ( ${ }^{\star}$ Correspondence: drshaymaahussein@gmail.com)

\begin{abstract}
This work evaluated the biological effects of three chitin synthesis inhibitors; Novaluron (Roxy), Teflubenzuron (Nomolt) and Hexaflumuron (Consult) against the second larval instar of Culex pipiens at different concentrations $(0.000001,0.00001,0.0001,0.001 \& 0.01 \mathrm{ppm})$.

The results showed that all three tested CSI's were toxic to the larvae as effective dose dependant. Novaluron was more effective followed by teflubenzuron and hexaflumuron. The toxicity index was $100,50 \& 25$ with Novaluron, teflubenzuron and hexaflumuron, respectively. All tested CSI's induced a significant prolongation in larval and pupal duration. Also, pupation rate decreased compared with control as well as reduction in adult emergence.
\end{abstract}

Keywords: Chitin synthesis inhibitors (CSI's), Novaluron, Teflubenzuron, Hexaflumuron, Culex pipiens.

\section{Introduction}

Mosquitoes are able to carry and spread disease to humans causing millions of deaths every year. In 2015 malaria alone caused 438000 deaths. The worldwide incidence of dengue has risen 30 -fold in the past 30 years, and more countries are reporting their first outbreaks of the disease. Zika, dengue, chikungunya, and yellow fever are all transmitted to humans by the Aedes aegypti mosquito. More than half of the world's populations live in areas where this mosquito species is present (WHO, 2019). In Egypt, mosquitoes as Culex 8 species, Anopheles 12 species and Aedes 4 species were encountered (Mikhail et al, 2009). C. pipiens plays the main role in transmission of filariasis bancrofti as in Egypt (Harb et al, 1993) and Rift Valley Fever (El Gebaly, 1978), West Nile virus (Wilson, 1991), and Sindbis fever Egypt (Monath, 1991). Anopheles plays the main role in malaria transmission (Saleh et $a l, 2016)$. Aedes aegypti and dengue hemorrhagic was encountered in Egypt (Morsy, 2018). Consequently, the sustained mosquito control efforts were important to prevent risky outbreaks from these diseases (El-Bahnasawy et al, 2013). The most common and widespread mosquitoes are members of $C$. pipiens complex.
The environmental friendly insect growth regulators (IGR's) have been used as agents that elicit their primary action on insect metabolism, ultimately interfering and disrupting the process of growth, development and metamorphosis of the target insects, particularly when applied during the sensitive period of insect development (Ghanim and Ishaaya, 2011).

The biological effects of hexaflumuron on $C$. pipiens were studied by Nassef et al. (2008) as well as other Culex species by Mulla et al. (1989), Amalraj and Velayudhan (1989), Amalraj and Das (1996) and Refaie (2008). The biological effects of novaluron on $C$. pipiens were studied by Djeghader et al. (2013) as well as other Culex species by Su et al. (2003), El-Barky et al. (2009) and Rajaskar and Jebanesan (2011). The biological effects of triflumuron on $C$. pipiens were studied by Rehimi and Soltani (1999) and Soltani et al. (1999). The biological effects of cyromazine on $C$. pipiens were studied by Cohen (1986) and Assar et al. (2016). The biological effects of other CSI's on $C$. pipiens were studied by Saleh and Ali (1987) using chlorfluazuron, Soliman et al. (2003) using Bay Sir and altosid and by Rajaskar and Jebanesan (2012) using buprofezin. 
The present study evaluated the biological effects of the CSI's, Novaluron, teflubenzuron and hexaflumuron on the widely distributed Culex pipiens larvae.

\section{Materials and Methods}

Origin of Culex pipiens: The strain of $C$. pipiens was obtained from the Research Institute of Medical Entomology, Ministry of Public Health and Population, Dokki, Giza, Egypt.

Rearing technique: The colony was maintained under the laboratory conditions of $27 \pm 2{ }^{\circ} \mathrm{C}$ and $75 \pm 5 \%$ R.H. (El-Bokl and Mowad 1996). The $2^{\text {nd }}$ instar larvae were collected for the bioassay tests. Five concentrations (0.000001, 0.00001, 0.0001, 0.001 \& $0.01 \mathrm{ppm})$ of the tested CSI's were tests. In each test, 25 larvae were put in clean plastic cup with $50 \mathrm{ml}$ stored tap water and treated with the CSI's. Each test was replicated four times; control experiments were performed by using tap water only. A mixture of ground dried bread and Brewer's yeast pellets (3:1) were added daily larval food. Dead larvae were daily recorded and removed. Larval mortality was corrected according to Abbott's formula (1987).
Statistical analysis: Data were subjected to probit analysis (Finney 1971) and Le Ora Soft Ware (1987) to give values of $\mathrm{LC}_{50}$. The toxicity index of the CSI's was calculated (Sun, 1950). Pupae were collected and transferred to other cups with cloth covers in emerging cages for adult emergence. Pupal duration, percent pupation and adult emergence were determined. The adult emergence reduction was calculated (Khazanie, 1979).

The tested chitin synthesis inhibitors: 1Novaluron (Rimon) (Roxy) $10 \%$ E C. (RS)1-[3-chloro-4-(1,1,2-trifluoro 2-trifluoromethoxyethoxy) phenyl]-3-(2,6-difluorobenzoyl) urea (Sigma-Aldrich Chemicals). 2- Teflubenzuron (Nomolt 15\% SC) 1-(3,5-dichloro-2,4-difluo-rophenyl)-3-(2,6 difluorobenzoyl) urea (Basev Limited, Egypt). 3- Hexaflumuron (consult 10\% EC)1-[3, 5-dichloro4-(1, 1, 2, 2-tetrafluoroethoxy) phenyl]-3(2, 6- difluorobenzoyl) urea (Dow Agroscience, Egypt).

Statistical analysis: Data were analyzed by one way analysis of variance (ANOVA) using SPSS (Ver. 21) software.

\section{Results}

The results were shown in tables $(1,2,3$, 4, 5, $6 \& 7$ ).

Table 1: Effect of chitin synthesis inhibitors (CSI's) on C. pipiens larval mortality treated as $2^{\text {nd }}$ larval instar.

\begin{tabular}{|c|c|c|c|c|}
\hline Concentrations (ppm) & Novaluron & Teflubenzuron & Hexaflumuron & $p$ \\
\hline Control & 5 & 5 & 5 & \\
\hline 0.000001 & 62 & 60 & 50 & NS \\
\hline 0.00001 & 84 & 70 & 62 & $*$ \\
\hline 0.0001 & 90 & 82 & 74 & $*$ \\
\hline 0.001 & 93 & 95 & 85 & $*$ \\
\hline 0.01 & 98 & 99 & 92 & NS \\
\hline$P$ & $*$ & $*$ & $*$ & \\
\hline
\end{tabular}

NS: Non Significant $(\mathrm{p}>0.05)$

*Significant $(\mathrm{p}<0.05)$

Table 2: Effect of the tested CSI's on C. pipiens larval mortality ${ }^{\#}$ treated as $2^{\text {nd }}$ larval instar.

\begin{tabular}{|c|c|c|c|c|}
\hline Concentrations $(\mathrm{ppm})$ & Novaluron & Teflubenzuron & Hexaflumuron & $p$ \\
\hline 0.000001 & 60.00 & 57.89 & 47.36 & NS \\
\hline 0.00001 & 83.15 & 68.42 & 60.00 & $*$ \\
\hline 0.0001 & 89.47 & 81.05 & 72.63 & $*$ \\
\hline 0.001 & 92.63 & 94.73 & 84.21 & $*$ \\
\hline 0.01 & 97.89 & 98.49 & 91.57 & NS \\
\hline$P$ & $*$ & $*$ & $*$ & \\
\hline
\end{tabular}

\#Corrected larval mortality

Table 3: $\mathrm{LC}_{50}, \mathrm{LC}_{75}$ and Toxicity index* of tested CSI's

\begin{tabular}{|c|c|c|c|}
\hline CSIs & Novaluron & Teflubenzuron & Hexaflumuron \\
\hline $\mathrm{LC}_{50}(\mathrm{ppm})$ & 0.0000005 & 0.000001 & 0.000002 \\
\hline Toxicity index & 100 & 50 & 25 \\
\hline
\end{tabular}


Table 4: Effect of CSI's on C. pipiens larval duration treated as $2^{\text {nd }}$ larval instar.

\begin{tabular}{|c|c|c|c|c|}
\hline Concentrations (ppm) & Novaluron (days) & Teflubenzuron (days) & Hexaflumuron (days) & $p$ \\
\hline Control & $11.32 \pm 0.10$ & $11.32 \pm 0.10$ & $11.32 \pm 0.10$ & \\
\hline 0.000001 & $12.81 \pm 0.19$ & $12.40 \pm 0.30$ & $11.92 \pm 0.21$ & $*$ \\
\hline 0.00001 & $13.16 \pm 0.65$ & $12.75 \pm 0.49$ & $12.20 \pm 0.37$ & $*$ \\
\hline 0.0001 & $15.50 \pm 0.53$ & $13.68 \pm 0.51$ & $14.29 \pm 0.59$ & $*$ \\
\hline 0.001 & $19.50 \pm 0.49$ & $14.55 \pm 0.54$ & $15.77 \pm 0.49$ & $*$ \\
\hline 0.01 & $19.80 \pm 0.50$ & $14.92 \pm 0.58$ & $15.96 \pm 0.51$ & $*$ \\
\hline$P$ & $*$ & $*$ & $*$ & \\
\hline
\end{tabular}

*Significant $(\mathrm{p}<0.05)$

Table 5: Effect of CSI's on percent pupation of C. pipiens larvae treated as $2^{\text {nd }}$ larval instar.

\begin{tabular}{|c|c|c|c|c|}
\hline Concentrations (ppm) & Novaluron & Teflubenzuron & Hexaflumuron & $p$ \\
\hline Control & 95 & 95 & 95 & \\
\hline 0.000001 & 38 & 40 & 50 & $*$ \\
\hline 0.00001 & 16 & 30 & 38 & $*$ \\
\hline 0.0001 & 10 & 18 & 26 & $*$ \\
\hline 0.001 & 7 & 5 & 15 & $*$ \\
\hline 0.01 & 2 & 1 & 8 & $*$ \\
\hline$P$ & $*$ & $*$ & $*$ & \\
\hline
\end{tabular}

Table 6: Effect of CSI's on pupal duration of C. pipiens larvae treated as $2^{\text {nd }}$ larval instar.

\begin{tabular}{|c|c|c|c|c|}
\hline Concentrations (ppm) & Novaluron (days) & Teflubenzuron (days) & Hexaflumuron (days) & $p$ \\
\hline Control & $7.53 \pm 0.06$ & $7.53 \pm 0.06$ & $7.53 \pm 0.06$ & \\
\hline 0.000001 & $8.93 \pm 0.14$ & $8.41 \pm 0.49$ & $9.06 \pm 0.26$ & $*$ \\
\hline 0.00001 & $10.12 \pm 0.55$ & $9.76 \pm 0.62$ & $11.43 \pm 0.46$ & $*$ \\
\hline 0.0001 & $11.43 \pm 0.51$ & $11.00 \pm 0.45$ & $12.88 \pm 0.42$ & $*$ \\
\hline 0.001 & $12.85 \pm 0.49$ & $13.52 \pm 0.51$ & $14.90 \pm 0.49$ & $*$ \\
\hline 0.01 & $13.12 \pm 0.52$ & $13.84 \pm 0.46$ & $15.00 \pm 0.50$ & $*$ \\
\hline$P$ & $*$ & $*$ & $*$ & \\
\hline
\end{tabular}

Table 7: Effect of CSI's on adult emergence of C. pipiens larvae treated as $2^{\text {nd }}$ larvae instar.

\begin{tabular}{|c|c|c|c|c|c|c|c|}
\hline \multirow{2}{*}{ Concentrations $(\mathrm{ppm})$} & \multicolumn{2}{|c|}{ Novaluron } & \multicolumn{2}{c|}{ Teflubenzuron } & \multicolumn{2}{c|}{ Hexaflumuron } & $P$ \\
\cline { 2 - 8 } & $\% \mathrm{AE}$ & $\% \mathrm{R}$ & $\% \mathrm{AE}$ & $\% \mathrm{R}$ & $\% \mathrm{AE}$ & $\% \mathrm{R}$ & \\
\hline Control & 79 & - & 79 & - & 79 & - & \\
\hline 0.000001 & 36 & 54.43 & 30 & 62.02 & 40 & 49.36 & $*$ \\
\hline 0.00001 & 12 & 84.81 & 26 & 67.08 & 30 & 62.02 & $*$ \\
\hline 0.0001 & 7 & 91.13 & 20 & 74.68 & 19 & 75.94 & $*$ \\
\hline 0.001 & 1 & 98.73 & 2 & 97.46 & 10 & 87.34 & $*$ \\
\hline 0.01 & 0 & 100 & 0 & 100 & 4 & 94.93 & $*$ \\
\hline$P$ & \multicolumn{3}{|c|}{$*$} & $*$ & & & \\
\hline
\end{tabular}

$\% \mathrm{AE}=$ percent of adult emergence, $\% \mathrm{R}=$ percent reduction in adult emergence, NS: Non Significant $(\mathrm{p}>0.05)$

The corrected larval mortality treated with different CSI's concentrations was given (Tabs. $1 \& 2$ ). Larval mortality was dose dependent with a significant difference in each CSI's. Novaluron was more toxic than teflubenzuron and/or hexaflumuron (Tab. 3). Treatment of $2^{\text {nd }}$ larval instar with CSI's significantly prolonged duration. This was dose dependent especially with novaluron than hexaflumuron and/or teflubenzuron (Tab. 4). Pupation of $2^{\text {nd }}$ instar larvae treated with different concentrations was highly decreased especially at higher concentrations $(0.001 \&$ $0.01 \mathrm{ppm})$. CSI's caused a significant pro- longation in pupal duration; hexaflumuron was more effective than novaluron and/or teflubenzuron (Tab. 6). All CSI's affected adult emergence (Tab. 7).

\section{Discussion}

In the present study, corrected larval mortality of $C$. pipiens treated with different CSI's concentrations showed larval mortality as dose dependent with significant difference for each CSI's. The $\mathrm{LC}_{50}$ was 0.0000005 , 0.000001 and $0.000002 \mathrm{ppm}$ with novaluron, teflubenzuron and hexaflumuron, respectively. CSI's toxicity index was $1,0.5 \& 0.25$, respectively. So, novaluron was more toxic 
than teflubenzuron, followed by hexaflumuron. These data agreed Mulla et al. (1989) who found that hexaflumuron induced larval mortality in C. quinquefasciatus and C. pipiens molestus. Vasuki and Rajavel (1992) reported that hexaflumuron were toxic to $C$. quinquefasciatus larvae at $0.01 \& 0.1 \mathrm{mg} / \mathrm{L}$. Also, Vasuki $(1992 ; 1993)$ found that hexaflumuron gave a high toxicity against all larval instars of $C$. quinquefasciatus, Anopheles stephensi and Aedes aegypti. Nassef et al. (2008) reported that hexaflumuron was toxic to $C$. pipiens larvae.

CSI's triflumuron (Dieghader et al, 2013) and novaluron and cyromazine (Assar et al, 2016) were toxic to $C$. pipiens larvae. Medina et al. (2002) reported differences in the toxicity of IGR's depend upon the cuticle penetration, distribution and excretion

In the present study, treatment of $2^{\text {nd }}$ larval instar of $C$. pipiens with CSI's resulted in a significant prolongation in larval duration, which was dose dependent with novaluron than with hexaflumuron and/or teflubenzuron. The larval duration with novaluron was $12.81,13.16,15.5,19.5 \& 19.8$ days at $0.000001,0.00001,0.0001,0.001 \& 0.01$ ppm, respectively, as 11.32 days in controls. This result agreed with Vasuki (1993) who reported that exposure of $3^{\text {rd }} \& 4^{\text {th }}$ instar larvae of $C$. quinquefasciatus to sublethal hexaflumuron doses significantly prolonged larval duration. Nassef et al. (2008) found that hexaflumuron prolonged $C$. pipiens larval duration. But, Triflumuron induced prolongation of $C$. pipiens larval period (Rehimi and Soltani, 1999; Soltani et al, 1999). Novaluron delayed $A$. aegypti larval development (Farnesi et al, 2012).

In the present study, pupation emerged from of $2^{\text {nd }}$ instar larvae treated with CSI's different concentrations was highly decreased compared to control, especially at higher concentrations $(0.001 \& 0.01 \mathrm{ppm})$. Teflubenzuron and novaluron were more effective than hexaflumuron. This agreed with Amalraj and Das (1996) who used hexaflumuron against $C$. quinquefasciatus, A. aegypti and
A. stephensi. Hexaflumuron decreased C. pipiens pupation (Nassef et al, 2008). The pupation of $C$. pipiens decreased by diflubenzuron (Kelada et al, 1981), and by cyromazine (Cohen, 1986; Assar et al, 2016).

In the present study, the CSI's caused a significant prolonged pupal duration $(\mathrm{P}<$ 0.05). Hexaflumuron was more effective than novaluron and/or teflubenzuron. Pupal duration was 9.06, 11.43, 12.88, $14.90 \& 15$ days at $0.000001,0.00001,0.0001,0.001 \&$ $0.01 \mathrm{ppm}$ with hexaflumuron, respectively, as as 7.53 day in controls. Such increase in pupal duration may reflect the disruption in metamorphosis. This agreed with Vasuki (1993) and Refaie (2008) using hexaflumuron on C. pipiens, Georghiou et al. (1975) and Kelada et al. (1981) using diflubenzuron and Assar et al. (2016) by using cyromazine.

In the present study, all the tested CSI's affected the emergence of adult $C$. pipiens. This effect was dose dependent. Novaluron and teflubenzuron completely inhibited adult emergence at $0.01 \mathrm{ppm}$. The adult emergence reduction was $54.43,84.81,91.13,98.73 \&$ $100 \%$ at $0.000001,0.00001,0.0001,0.001 \&$ $0.01 \mathrm{ppm}$ of novaluron, while with teflubenzuron, reduction was 62.02, 67.08, 74.68, $97.46 \& 100 \%$, respectively. This reduction agreed with Nassef et al. (2008). Also, hexaflumuron reduced adult emergence of $C$. tarsalis (Mulla et al, 1989) and C. quinquefasciatus (Amalraj and Velayudhan 1989; Vasuki and Rajavel, 1992; Vasuki 1993; 1997). Novaluron inhibited adult $C$. quinquefasciatus emergence (Su et al, 2003; El-Barky et al, 2009; Rajasker and Jebansan, 2011; Rajasker and Jebansan, 2012). Soliman et al. (2003) found that $\mathrm{LC}_{30}$ of Bay Sir and altosid reduced adult emergence of $C$. pipiens. Diflubenzuron caused inhibition of adult emergence of $C$. pipiens (Mulla et al, 1975; Takahoshi and Ohtaki, 1976; Eshita and Kurihara, 1977; Alizaev, 1986; Luna and Daza, 1992; Cetin et al, 2006). Generally, the adult emergence decrease could be due to the fact that IGR's block the maturation of imagine discs that primordial of many adult integu- 
mentary structures in endopterygote insects or due to deformation of adult chitin (Schnidermann, 1972; Degheele, 1990).

\section{Conclusion}

In fact, mosquitoes can transmit different bacteria, viruses or parasites diseases worldwide. Climate, travel and trade can influence their spread. The present data proved that the CSI's possess a potent insecticidal activity on $C$. pipiens larvae and can be successfully used with other mosquito larvae.

\section{References}

Abbott, W, 1987: A method of computing the effectiveness of insecticide, J. Am. Mosq. Cont. Assoc. 3, 20:302-3.

Alizaev, GU, 1986: Practical tests of dimilin in the control of mosquito larvae in Baku. Meditsin. Parazit. Bol.1: 32-35.

Amalraj, D, Das, PK, 1996: Toxicity of insecticides to Toxorhynchites splendens and three vector mosquitoes and their sublethal effect on biocontrol potential of the predator. Southeast Asian J. Trop. Med. Publ. Hlth. 27, 1:154-9.

Amalraj, D, Velayudhan, R, 1989: Insect growth regulator XRD-473(OMS3031), a prospective compound for control of mosquito vectors. Proc. Indian Acad. Sci. 98, 5:325-9.

Assar, AA, Abo-El-Mahasen, M, Afifi, AF, Rady, AA, 2016: Biological and histopathological effects of cyromazine on the larvae of Culex pipiens (Diptera: Culicidae). J. Biosci. Appl. Res. 2, 4:263-73.

Cetin, H, Yanikoglu, A, Cilek, JE, 2006: Efficacy of diflubenzuron, a chitin synthesis inhibitor, against Culex pipiens larvae in septic tank water. J. Am. Mosq. Cont. Assoc. 22, 2:-343-5.

Cohen, J, 1986: Observation of the effect of cyromazine on inhibition of larval mosquito development in diluted waste water. J. Am. Mosq. Cont. Assoc. 2, 3:367-8.

Degheele, D, 1990: Chitin synthesis inhibitors: Effects on Cuticle Structure and Components.377-388. In: J. E. Casida (ed.), Pesticides and alternatives. Elsevier Amsterdam.

Djeghader, N, Boudjelida, H, Bouaziz, A, SoItani, N, 2013: Biological effects of benzoylphenylurea derivative (Novaluron) on larvae of $\mathrm{Cu}$ lex pipiens (Diptera: Culicidae). Pelagia Research Library, Adv. Appl. Sci. Res. 4, 4:449-56.

El-Bahnasawy, MM, Khater MK, Morsy, TA, 2013: Mosquito borne west Nile virus infection: Is it threating to Egypt or a neglected endemic disease? J. Egypt. Soc. Parasitol. 43, 1:87-102.

El-Barky, N.M, Amer, AE, Kandeel, MA, 2009: Ovicidal activity and biological effects of Radiant and Hexaflumuron against eggs of pink bollworm, Pectinophora gossypiella (Saunders) (Lepidoptera: Gelechiidae). Egypt. Acad. J. Biol. Sci. 2, 1:23-36.

El-Bokl, MM, Moawad, HM, 1996: Evaluation of some plant extracts as mosquito larvicides, Ain Shams Sci. Bull. 34:351-62.

El-Gebaly, RM, 1978: Epidemiological study of outbreak of rift valley fever in military personnel. J. Egypt. Pub. Hlth. Ass., 53:141-50.

Eshita, Y, Kurihara, T, 1977: Effect of the inhibition of the insect development by dimilin against four species of mosquitoes. Japan. J. Sanit. Zool. 28, 3:333-6.

Farnesi, LC, Brito, JM, Linss, JG, PelajoMachado, M, Valle, D, et al, 2012: Physiological and Morphological aspects of Aedes aegypti developing larvae: Effects of the chitin synthesis inhibitor Novaluron. PLoS ONE 7, 1:e30363.

Finney, DJ, 1971: Probit analysis In: Finney, D.J.(ed) $3^{\text {rd }}$ Ed. Cambridge Univ. Press, London. Georghiou, GP, Lin, CS, Mulhern, TD, 1975: Investigations on the mode of action of dimilin (TH 6040) against mosquitoes. Proce. $43^{\text {rd }}$ Ann. Conf. California Mosq. Cont. Assoc. 5:84 -8.

Ghanim, M, Ishaaya, I, 2011: Insecticides with novel modes of action mechanism and resistance management. In: Tolerance to Environmental Contaminants, Edition, Publisher: CRC Press.

Harb, M, Faris, R, Gad, AM, Hafez, O, Ramsy, R, et al, 1993: Resurgence on lymphatic filariasis in the Nile Delta. Bull. WHO., 71:49-54.

Kelada, NL, Gaaboub, IA, Rawash, IA, 1981: The effects on reproduction and morphometrics of females of Culex pipiens after treatment of larvae with six insect growth regulators. J. Agric. Sci. 96, 3:611-8.

Khazanie, R, 1979: Elementary statistics In: Khazanie, R. (ed) (Good Year Publishing Co.) California, USA.

Le Ora Soft Ware, 1987: Polo-PC: A user's guide to Probit or Logit analysis. Le Ora Soft Ware; 1119 Shattuk Ave., Berkeley, C.A.

Luna, JE, Daza, L, 1992: Evaluation of diflubenzuron for the control of larvae and pupae of Culex pipiens in Bucaramanga. Rev. Colomb. Entom. 18, 1:23-5.

Medina, P, Smagghe, G, Budia, F, Del-Estal, P, Tirry, L, Vinuela, E, 2002: Significance of penteration, excretion and transovarial uptake to 
toxicity of three growth regulators in predatory lacewing adults. Arch. Insect Biochem. Physiol. 51, 2:91-101.

Mikhail, MW, Al-Bursheed, KhM, Abd ElHalim, AS, Morsy, TA, 2009: Studies on mosquito borne diseases in Egypt and Qatar. J. Egypt. Soc. Parasitol. 39, 3:745-56.

Monath, TP, 1991: Viral febrile illness. In: Strickland, G.T. (ed.), Hunter's Tropical Medicine. W.B. Saunders, Philadelphia.

Morsy, TA, 2018: Aedes aegypti and dengue virus infections. J. Egypt. Soc. Parasitol. 48, 1: 183-96.

Mulla, MS, Darwazeh, HA, Schreiber, ET, 1989: Impact of new insect growth regulators and their formulation on mosquito larval development in impoundment and flood water habitats. J. Amer. Mosq. Control Assoc. 5, 1:15-20.

Mulla, MS, Majori, G, Darwazeh, HA, 1975: Effects of the insect growth regulator, dimilin or TH-6040 on mosquitoes and some non-target organisms. Mosq. News 35, 2:211-6.

Nassef, NE, El- Nahas, NS, Shams, SA, Assar, AA, 2008: Biological and morphogenetic effects of some insect growth regulators on Culex pipiens. Egypt. J. Med. Sci. 29, 1:707-23.

Rajaskar, P, Jebanesan, A, 2011: Influence of short time exposure to an insect growth regulator, novaluron on mortality and adult emergence of mosquitoes. Pestology 35, 6:43-7.

Rajaskar, P, Jebanesan, A, 2012: Efficacy of IGRs compound novaloron and buprofezin against Culex quinquefasciatus mosquito larvae and pupal control in pools, drains and tanks. Int. J. Res. Biol. Sci. 2, 1:45-7.

Refaie, BM, 2008: Efficacy of pyriproxyfen against Culex pipiens under laboratory conditions. Proc. $4^{\text {th }}$ Conf. Appl. Entomol. 39:46-8.

Rehimi, N, Soltani, N, 1999: Laboratory evaluation of alsystin, a chitin synthesis inhibitor, against Culex pipiens pipiens (Diptera: Culicidae): effects on development and cuticle secretion. J. Appl. Entomol. 123, 7:437-41.

Saleh, AMA, Adam, SM, Ibrahim, AMA, Morsy, TA, 2016: Malaria: A general mini-review with reference to Egypt. J. Egypt. Soc. Parasitol. 46, 1:35-48.

Saleh, MS, Ali, MI, 1987: Biological effects of three insect growth regulators on Culex pipiens. Anzeig. Schadlings. Pflanzens.60, 2:34-7.

Schineidermann, HA, 1972: Insect hormone and insect control. In: Insect Juvenile Hormone,
Chemistry and Action. Academic Press, New York. London.

Soliman, BA, Soliman, MA, El-Hussani, IM, Sief, AI, 2003: Impact of some larvicidal insect growth regulators and their combination with a surfactant agent on a surfactant agent on Culex pipiens (Diptera: Culicidae). J. Egypt. Ger. Soc. Zool. 40, E:111-23.

Soltani, N, Rehimi, N, Drardja, H, Bendali, F, 1999: Triflumuron activity against Culex pipiens and two larvivorus impacts on non-target species. Ann. Entomol. Soc. Fra. France, 35:59-64.

Su, T, Mulla, MS, Zaim, M, 2003: Laboratory and field evaluation of novaluron, a new insect growth regulator IGR against Culex pipiens mosquitoes. J. Amer. Mosq. Control Assoc. 19, 4:408-18.

Sun, YP, 1950: Toxicity index-An improved method of comparing the relative toxicity of insecticides. J. Econ. Entomol. 43: 45-53.

Takahoshi, M, Ohtaki, T, 1976: A laboratory evaluation of the IGR, TH 6040, against Culex pipiens pallens and Culex tritaeniorhynchus. Japan. J. Sanit. Zool. 27, 4:361-5.

Vasuki, V, 1992: Adult longevity of certain mosquito species after larval and pupal exposure to sublethal concentrations of an insect growth regulator, hexaflumuron. Southeast Asian J. Trop. Med. Publ. Hlth. 23, 1:121-4.

Vasuki, V, 1993: Sublethal effects of hexaflumuron, an IGR on developmental duration and sex ratio of three vector mosquitoes. Trop. Biomed. 10, 1:9-14.

Vasuki, V, 1997: Effect of hexaflumuron, a chitin synthesis inhibitor, on mating success of three species of vector mosquitoes. Int. J. Trop. Ins. Sci., 17, 2:265-8.

Vasuki, V, 1999: Influence of IGR treatment on oviposition of three species of vector mosquitoes at sublethal concentrations. Southeast Asian J. Trop. Med. Publ. Hlth. 30, 1:200-3.

Vasuki, V, Rajavel, AR, 1992: Influence of short time exposure to an insect growth regulator, hexaflumuron, on mortality and adult emergence of vector mosquitoes. Mem. Inst. Oswaldo Cruz 87, 2:275-83.

WHO, 2019: Neglected tropical diseases: Vector ecology and management (VEM) Geneva, Switzerland.

Wilson, ME, 1991: A World Guide to Infection: Diseases, Distribution, Diagnosis. Oxford, Oxford University Press. 